Communication

\title{
Determining Coalbed Methane Production and Composition from Individual Stacked Coal Seams in a Multi-Zone Completed Gas Well
}

\author{
Nino Ripepi ${ }^{1,2}$, Kyle Louk ${ }^{2}$, Joseph Amante ${ }^{2}$, Charlies Schlosser ${ }^{2}$, Xu Tang ${ }^{2, *}$ \\ and Ellen Gilliland ${ }^{1,2}$ \\ 1 Department of Mining and Minerals Engineering, Virginia Polytechnic Institute and State University, \\ Blacksburg, VA 24060, USA; nripepi@vt.edu (N.R.); elleng@vt.edu (E.G.) \\ 2 Virginia Center for Coal and Energy Research Center, Virginia Polytechnic Institute and State University, \\ Blacksburg, VA 24060, USA; aklouk@vt.edu (K.L.); josamant@vt.edu (J.A.); charless@vt.edu (C.S.) \\ * Correspondence: xutang@vt.edu; Tel.: +1-(540)-998-7174
}

Received: 28 August 2017; Accepted: 27 September 2017; Published: 2 October 2017

\begin{abstract}
This work proposes a novel and cost-effective approach to determine coalbed methane (CBM) production and composition from individual coal seams in a multi-zone completed CBM well. The novel method uses water to cover individual coal seams in a low pressure CBM well followed by an Echometer fluid level survey to determine the water level. Corresponding gas flow measurements and natural gas chromatography analysis are used to determine gas production and composition from unique zones. A field test using this technology is conducted in Central Appalachia for a multi-zone CBM well containing 18 coal seams. Test results show that the shallow coal seams contribute the majority of the total CBM production in this multi-zone well, and the deeper coal seams contain more heavy hydrocarbons like ethane and propane.
\end{abstract}

Keywords: multi-zone CBM well; CBM production; CBM composition

\section{Introduction}

A typical coalbed methane (CBM) well in Central Appalachia is produced from multiple stacked thin coal seams over approximately 1000 feet of stratigraphic section [1-3]. These coal seams are typically grouped together in zones and hydraulically fractured with a nitrogen-foam completion strategy in order to increase the permeability of the coal to allow for commercial gas flow $[4,5]$. Even though the gas content and composition for each coal seam could be known in advance through desorption testing in the exploration stage, it is challenging to determine the contribution of each coal seam or zone as part of the total flow from the CBM well during the production stage [6,7]. This can be attributed to the complex nature of in situ coal reservoir conditions such as in situ stress, coal permeability, coal rank, the saturation status, and heterogeneous physical properties of coal [6-8]. The CBM in deeper coal seams may not be produced as easily because of the low permeability induced by high in situ vertical stress when compared with shallow coal seams [9]. Furthermore, the direction, length, and proppant placement from the hydraulic fracture stimulation is not known and likely varies significantly by coal seam. In fact, it has been shown that during zone stimulation of stacked coal seams, some of the seams do not take any of the proppant [4]. The application of production logging by use of a spinner survey and production data analysis could be very helpful in determining the contribution of each coal seam [3,10-12], but it is very difficult because of low pressure and flow rates, as well as expensive because a downhole pump would need to be removed and water swabbed from the wellbore. Therefore, developing a feasible and cost-effective method is needed in order to determine CBM production and composition from individual coal seams in multi-zone CBM wells. 
Additionally, geological sequestration of carbon dioxide in coal seams is of interest because enhanced gas recovery due to injected carbon dioxide could reduce the total cost of carbon sequestration [12,13]. Researchers from Virginia Tech have injected 14,000 tons of carbon dioxide into three CBM wells in Central Appalachia to investigate the feasibility of injecting carbon dioxide into unmineable coal seams while simultaneously enhancing CBM recovery [14-17]. One of the objectives of this project is to track the migration of carbon dioxide throughout the injection and post-injection phases, including returning the legacy wells to production. Since the carbon dioxide is injected into multiple stacked coal seams, how the injected carbon dioxide is stored in each coal seam is still under investigation [17]. In order to answer this question, a cost-effective approach to determine the amount of the injected carbon dioxide produced from each coal seam is needed, and this technique will be applied when the three injection wells are reconverted to CBM production wells.

A typical multi-zone CBM well in Central Appalachia has 4.5 inch casing cemented through the wellbore with perforations shot into each of the stacked coal seams so that gas and water can flow into the well. Hydraulic fracture treatments are typically done by grouping coal seams in three or four zones and stimulating with $75 \%$ by volume (quality) of nitrogen gas foamed as a carrier fluid to transport proppant in order to break down the coals and place sand to hold open the fractures. After hydraulic fracture treatments and flowback, CBM wells in this basin are configured with a downhole pump that can produce water up a 2-3/8 inch tubing while gas is simultaneously produced up the annulus of the tubing. Water is pumped from the well at predetermined intervals and lengths of time throughout the day in order to keep water from covering any of the coal seams that are producing gas. The gas production is metered at the surface by calculating the pressure differential across an orifice plate. Gas production from these wells is typically at very low pressures; $1-5$ psi over atmosphere is common.

This work proposes a novel and cost-effective method to determine the gas production and composition from individual coal seams in a multi-zone CBM well by combining an Echometer fluid level survey while systematically killing the production from the well. A field test using this method is conducted in Central Appalachia for a multi-zone CBM well containing 18 unique coal seams. The gas production and composition for coal seams of interests in this multi-zone test well are analyzed.

\section{Theory, Method, and Field Test}

\subsection{Theory}

In water-saturated coals, the production of CBM is directly related to the drainage of water from the coal seam. Dewatering is usually required to depressurize the seam and enable the gas to flow out of the coal and into the production well $[6,7,18,19]$. Simply speaking, a water pump is placed at the bottom of the CBM well to dewater the well, followed by CBM production. The well kill test is accomplished by injecting water in the annulus of the wells in order to slowly cover producing seams and thus kill the production from those covered coal seams because the hydrostatic pressure in the column of water is greater than the low coal seam gas pressure. An Echometer fluid level survey is taken immediately after each water injection phase to determine the water level. The CBM production and composition for these seams can be determined by the flow rate and gas composition analysis of the produced gas from the well head. The theory of this novel well kill test allows the production from each coal seam to be separated from a multi-zone CBM well one by one, which paves the way for determining the gas contribution of each unique coal seam or groups of coal seams if the seams are located in close proximity to each other stratigraphically. The Echometer can compute the distance down-hole to the surface of the liquid in between the annulus of the tubing and the casing. This is accomplished by using the speed of sound of the carrier gas based on the principle of creating a sound wave that travels from the surface, down the casing, reflects off the surface of the fluid, and bounces back to the top of the well where the sound wave is picked up by a sensitive pressure transducer $[20,21]$. By combining a gas flowmeter and natural gas chromatography analysis of the produced gas from the CBM well, the gas production and composition contributed by each coal seam can be determined. 


\subsection{Method}

The general test procedure is illustrated by a CBM well containing three coal seams labeled A, B, and C. In step (i), the three coal seams are producing at the same time. D1 is obtained by an Echometer fluid level survey as the baseline. Accumulated gas production is recorded as $V_{c}$, and the natural gas is sampled from a stable production gas flow to determine each composition as $M_{1 c}, M_{2 c}, M_{3 c}$, $\ldots, M_{n c}$, where the unit is percentage (\%), and $n$ represents the total number of components. In step (ii), a certain amount of water is injected into the CBM well through a water truck followed by an Echometer fluid level survey until coal seam C is saturated and the water level is D2. It is worth noting that multiple Echometer surveys may be needed in order to make sure the water well is stable, because some dry coal seams may vacuum in the injected water. When the gas flow is stable, the accumulated gas production is recorded, $V_{b}$, and the composition of gas sample is analyzed as $M_{1 b}, M_{2 b}, M_{3 b}, \ldots$, $M_{n b}$. In step (iii), an additional slug of water is injected to saturate coal seam B following the same procedure in step (ii), and D3 is obtained by an Echometer fluid level survey. When the gas flow is stable, the gas flow is recorded, $V_{a}$, and the composition of gas sample is analyzed as $M_{1 a}, M_{2 a}, M_{3 a}$, $\ldots, M_{n a}$. By combining these three steps, the gas production and composition contributed by each coal seam can be determined.

Utilizing the first and second test case in Figure 1 as an example, the gas production from Group C coal seams can be calculated by the Equation (1).

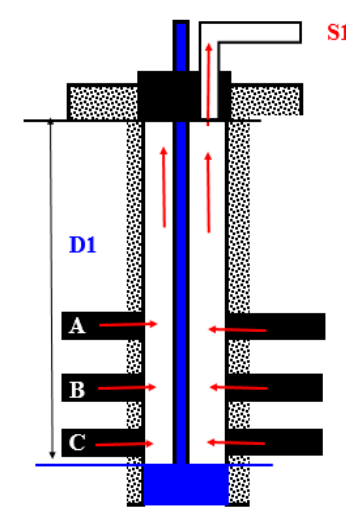

(i)

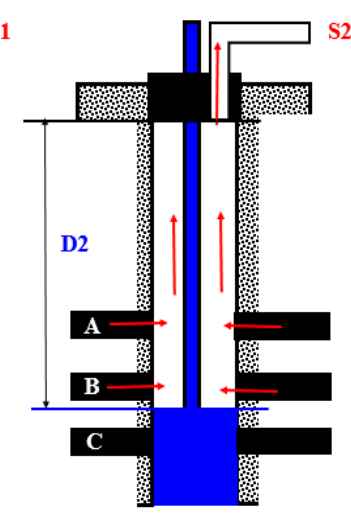

(ii)

Water $\longrightarrow$ CBM flow

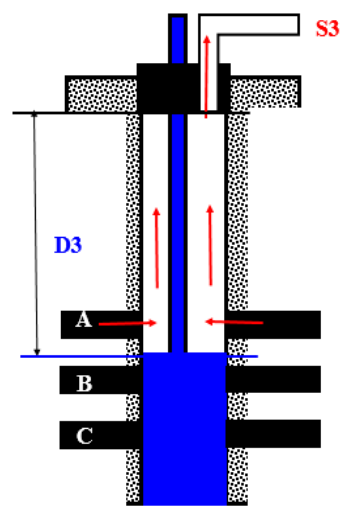

(iii)

Figure 1. Simplified procedures for determining gas production and composition of each coal seam (groups A, B and C) from a multi-seam coalbed methane (CBM) well.

Gas production of Group C coal seams $\left(G_{c}\right)$, which is always positive,

$$
G_{c}=V_{c}-V_{b}
$$

Each composition of CBM from Group $C, M_{n G c}$, can be calculated by,

$$
M_{n G c}=\frac{V_{c} \cdot M_{n c}-V_{b} \cdot M_{n b}}{V_{c}-V_{b}}
$$

\subsection{Field Tests}

The coal field for this study is located in Buchanan County, Virginia, where there are typically 15-20 coal seams completed from the Pocahontas and Lee formations, averaging $0.3 \mathrm{~m}(1.0 \mathrm{ft})$ in thickness, for net reservoir thicknesses of approximately 4.5-6.0 m (15-20 ft) [14]. The general stratigraphic column for coals completed in this study well is shown in Figure 2 and consists of 18 different coal seams. 


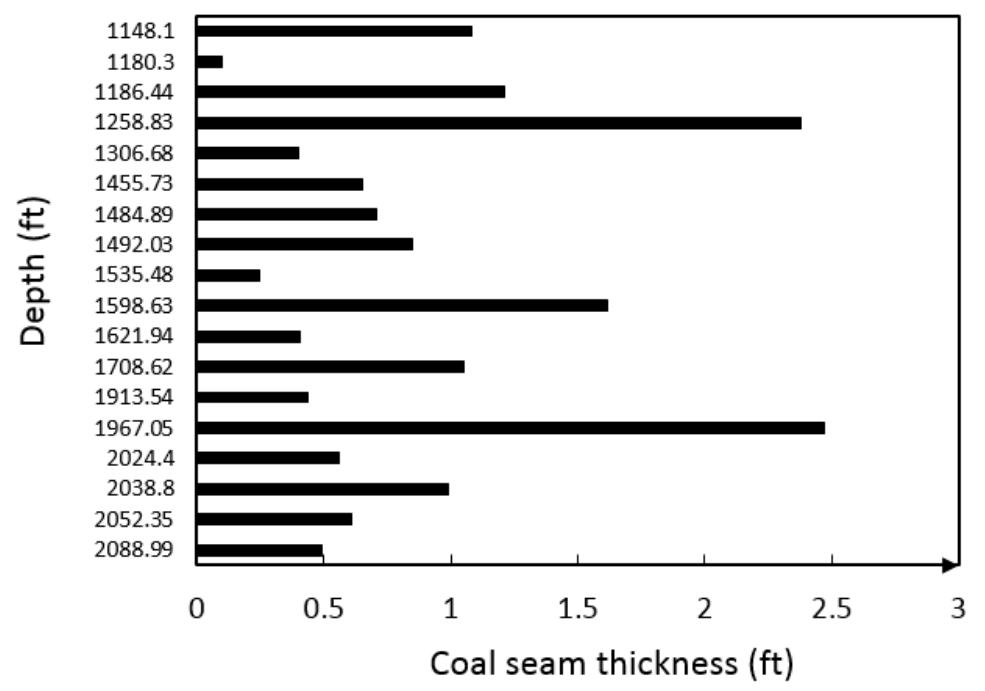

Figure 2. Coal seam thickness in the test well.

The field test consists of five cyclic sampling tests performed by the proposed method. Both collar counting and acoustic velocity tests are used with Echometer software to accurately determine the water level in the CBM well. The instantaneous accumulated gas production flow is obtained from a total flow meter at the test well which is manufactured by ABB (ASEA Brown Boveri) Inc. The CBM sample is obtained thorough a gas sample cylinder and sampled CBM is analyzed by a portable Natural Gas Chromatograph (NGC).

The experiment started with a stable baseline for both the gas composition and the liquid level. Water was then injected into the well in varying intervals to increase the hydrostatic pressure to kill coal seams at different depths to obtain new and stable gas compositions and flow rates. This cycle was repeated until the well was effectively killed and the flowrate was zero. Detailed information about the Echometer liquid level measurement and natural gas sampling and analysis method are referred to the Supplemental Materials.

\section{Test Results}

\subsection{Covered Coal Seams and Production Behavior}

Based on the Echometer test results, the covered coal seams can be classified into five individual groups, G1-G5, and at five different water level depths, $1486 \mathrm{ft}, 1858 \mathrm{ft}, 1965 \mathrm{ft}, 2017 \mathrm{ft}$, and $2150 \mathrm{ft}$, as shown in Figure 3a. The net coal seam thickness in each individual group of coals are different, as shown in Figure 3b. It is worth noting that each phase of the test lasts from 30-60 min, which enables enough time to inject water, stabilize gas flow, take an Echometer reading, and sample gas for gas composition analysis. It is extremely important to stabilize the gas flow as pressure is allowed to build during the water injection and Echometer test.

The accumulated gas production for each phase of the well test shows that when water kills more coal seams, the accumulated gas production decreases, as shown in Figure 4a. The gas production from each group shows that the shallow groups, G1 and G2, produce more gas when compared with that of the deep G3, G4, and G5 groups in Figure 4b. The gas production per unit coal thickness from each coal group shows that G3 has the highest gas production followed by G2, G1, G5, and G4 in Figure 4c. Based on the above observations, it can be concluded that coal seams in shallow groups (G1, G2, and G3) contribute more to the total gas production than the deep groups of coals (G4 and G5). Unfortunately, it is difficult to ascertain the correct reasons behind this observation because there are a number of affecting factors, such as coal permeability, in situ stress, gas content, gas pressure, and water saturation status, in this real scenario that are coupled and complex. 


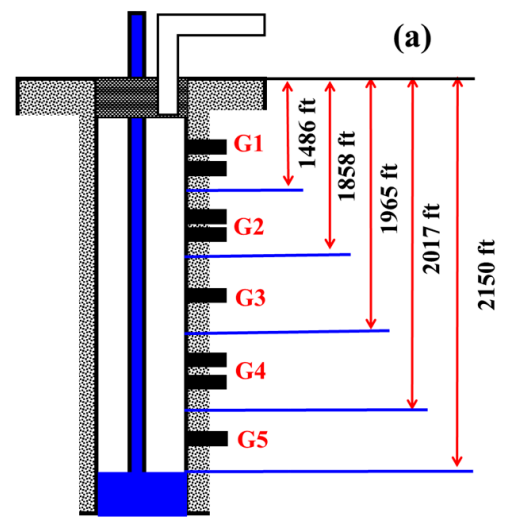

(b)

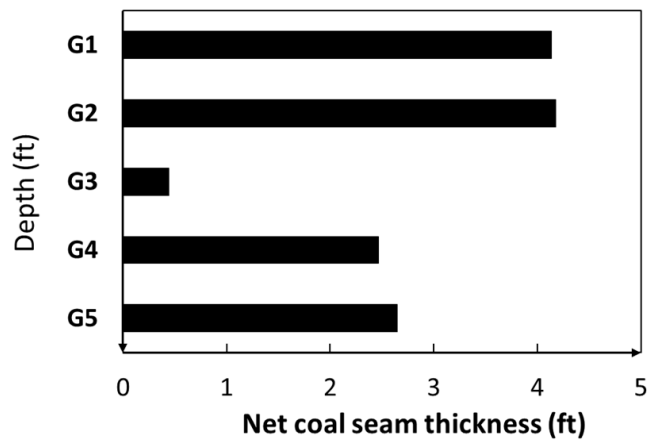

Figure 3. Water levels from Echometer tests (a) and net thickness of water-covered coal seams in each test (b). G1-G5 represents five individual groups of coals for each test, blue color represents water/water level in the CBM well, and black bar represents net coal seam thickness in each group.

(a)

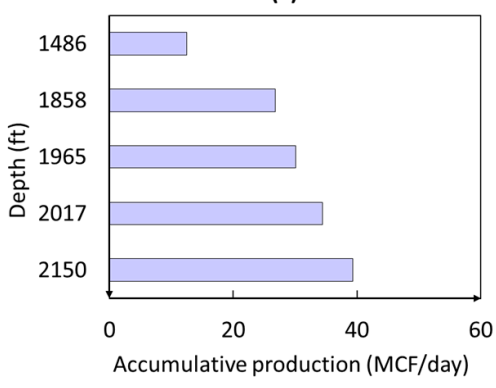

(b)

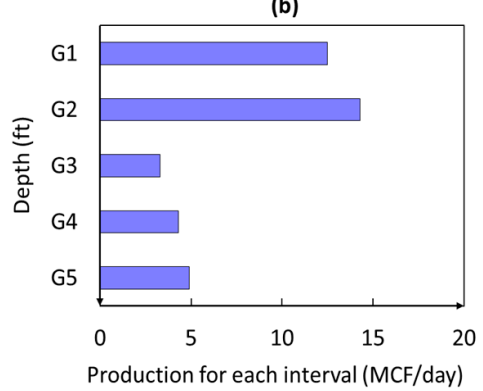

(c)

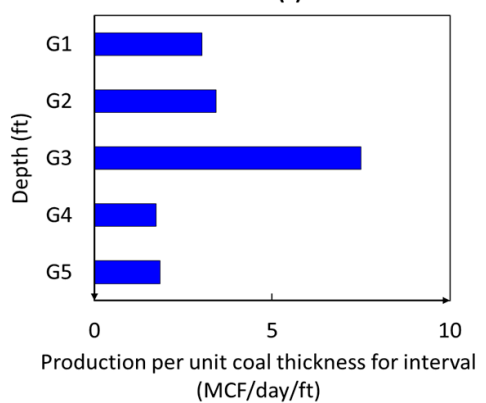

Figure 4. Gas production from each well kill test: (a) represents accumulative gas production from shallow coal seams to deep coal seams; (b) gas production at each coal seam interval; and (c) represents the gas production per unit coal thickness for each intervals.

\subsection{CBM Composition in Each Tested Group}

For each phase of the well kill test, composition analysis of the produced gas shows that methane content dominates the natural gas content, averaging around 98\% in Figure 5a. The volume percentage of heavier hydrocarbons (ethane, propane, and butane) shows an increasing trend when deep coal seams produce, which indicates that heavier hydrocarbons come from deeper coal seams, as shown in Figure $5 b$.

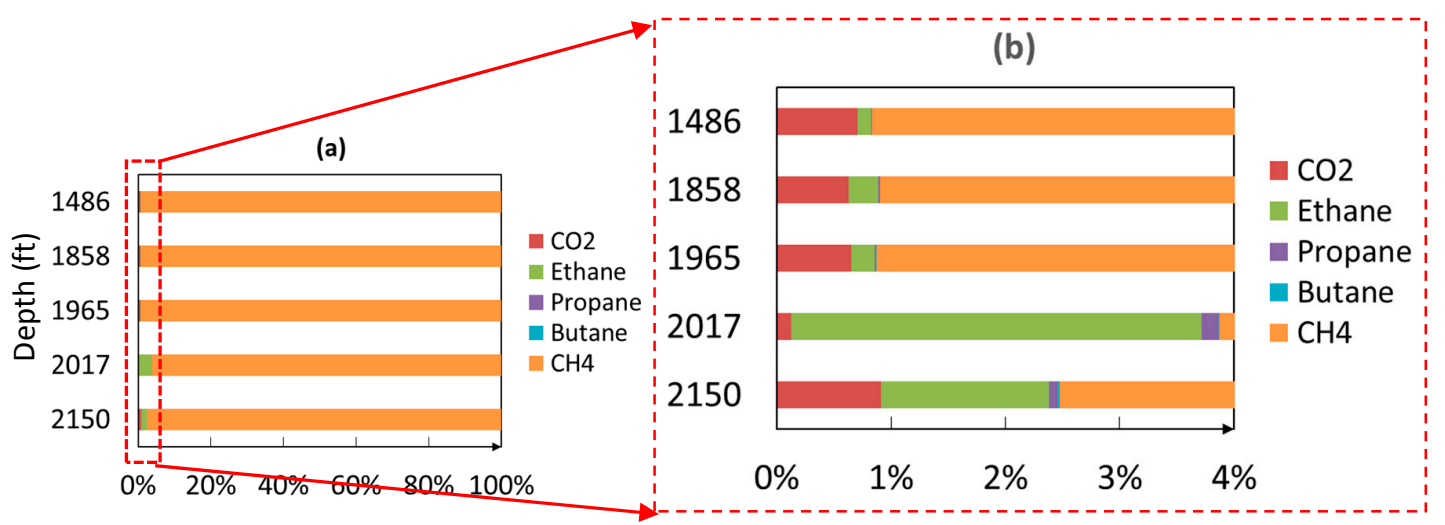

Figure 5. Gas composition of accumulated CBM sample: (a) represents gas composition of accumulated CBM sample from shallow seams to deep seams and (b) represents an enlarged section of Figure 5a. 
According to the mass balance, the natural gas composition of each group can be obtained from the accumulated gas production data from each phase of the well kill test. The methane content of each group also averages around 98\%, as shown in Figure 6a. It can also be seen that the deep groups, G3, G4, and G5, have significantly higher heavier hydrocarbons such as ethane, propane, and butane than the shallow groups, namely, G1 and G2, as shown in Figure 6b.

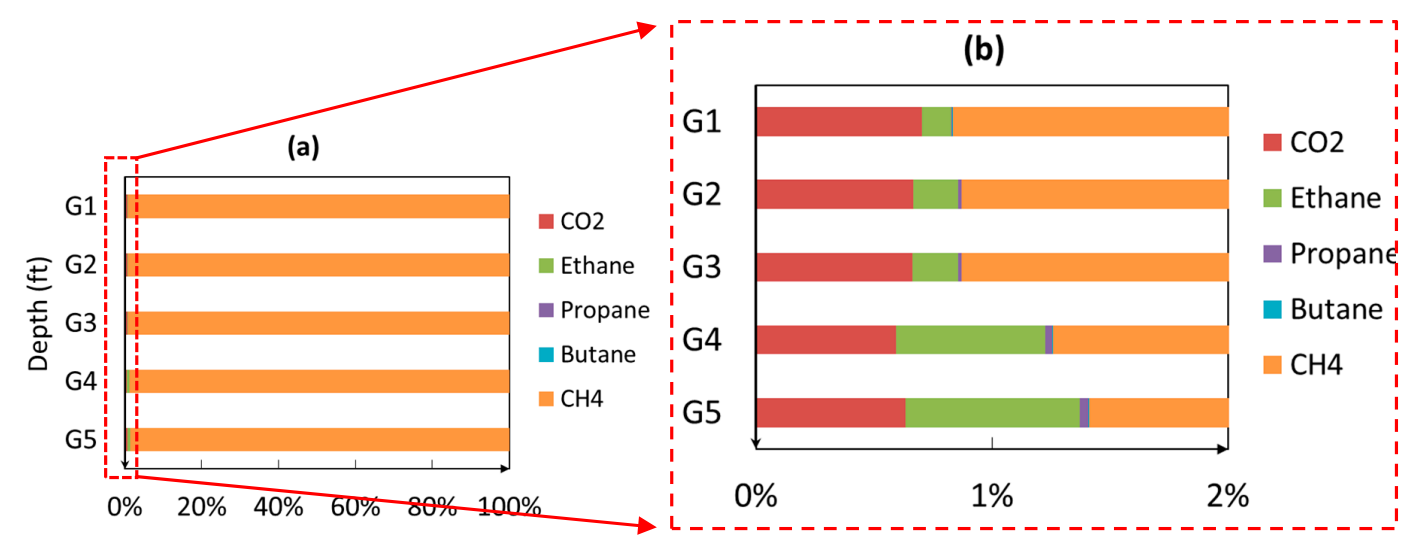

Figure 6. Gas composition for each coal seam interval at different depths: (a) Gas composition for each coal seam interval at different depth, and (b) represents an enlarged section of Figure $6 a$.

\section{Discussion and Outlook}

This work proposes a novel and cost-effective engineering approach to determine CBM production and composition from individual coal seams in multi-zone coalbed methane wells. This technology uses water to cover coal seams of interest in a multi-zone CBM well to kill their production, followed by an Echometer fluid level survey to determine the water level as well as the corresponding natural gas production measurement and gas composition analysis. The field test for a multi-zone CBM well using this approach reveals that the produced CBM contains around $98 \%$ methane, the shallow coal seams contribute the majority of the total CBM production in this multi-zone well, and the deep coal seams contain more heavy hydrocarbons like ethane and propane. The proposed approach will be applied to track produced carbon dioxide from an on-going huff-and-puff test.

The purpose of this communication is to disclose this latest technology to engineers and scholars in the natural gas industry and to inspire in-depth modeling and continued research, as the topic in this work has not been previously studied. Determining the gas contribution from individual coal seams in multi-seam CBM wells is extremely important because this not only influences the CBM production forecast, but also affects the composition of the produced CBM. This work not only provides a preliminary solution for this problem, but also discloses some more interesting scientific questions which warrant further investigation. Do deep coal seams always contain more heavier hydrocarbons than shallow coal seams? Does the gas composition of produced CBM change with time? Why do deep coal seams contribute less gas production in a multi-zone CBM well? As shallow coal seams are depleted of gas, will the deep coal seams contribute more in the future? Is the nitrogen in the production stream from the fracture treatment? If so, is nitrogen produced from a specific zone related to flow rate or does that change over time?

All of these questions and many more remain unclear, but could be solved by utilizing this technology to evaluate more CBM wells as well as by tracking individual CBM wells over time. The authors believe that if a larger well kill dataset was put together for a group of CBM wells, one could analyze the produced gas for heavier hydrocarbons and estimate how much of the gas was being produced from the deeper versus the shallower coal seams. This data would allow a CBM operator to make better-informed decisions on which coal seams to target with respect to initial stimulation and if it would be profitable to re-stimulate coals or groups of coals that were previously not good producers. 
This also means if the majority of the gas is being produced early on in the life of the well from the shallow seams, then it might prove to be more economical to drill and complete those seams versus spending the money to drill deeper and produce the deeper seams. In order to verify this hypothesis, one would need to repeat this test for a single well annually over the first five years of production of that well. Next, decline curves of production by seam could be created for that five-year period, and a full economic analysis could be performed that would include drilling, completion, and operating costs on a seam basis and the market price of gas [22]. Since heavier hydrocarbons such as propane and butane have higher calorific value than methane and a higher market value, this technology also empowers CBM operators to preferentially produce gases with heavier hydrocarbons as the exact gas composition is known. Alternatively, if $\mathrm{CO}_{2}$ is being produced in quantities that reduce the market price of the gas or require the use of expensive removal technologies, a CBM operator could identify the contribution of $\mathrm{CO}_{2}$ by seam and not complete that seam. The information disclosed from this technology could prove vital to a CBM operator who is trying to maximize profit.

Supplementary Materials: The following are available online at www.mdpi.com/1996-1073/10/10/1533/s1, Figure S1: Schematic (a) and real test (b) of Echometer liquid level survey; Figure S2: Acoustic test with reflection surface for depth; Figure S3: Collar counting for depth; Figure S4 Gas composition sampling and analysis facilities; Figure S5: ASTM Method D1945-96 Natural Gas Analysis; Figure S6 Sample NGC Chromatographic Report.

Acknowledgments: This research was supported in part by the U.S. Department of Energy through the National Energy Technology Laboratory's Program under Contract No. DE-FE0006827.

Author Contributions: N.R. provided the main idea, designed and supervised the project; N.R., K. L., J. A. and C.S. conducted field and lab experiments; X.T., C.S. and N.R. analyzed the data and drafted the manuscript; and C.S. and E.G. reviewed and verified results. All authors reviewed the manuscript.

Conflicts of Interest: The authors declare no conflicts of interest.

\section{References}

1. Nolde, J.E.; Spears, D. A preliminary assessment of in place coalbed methane resources in the Virginia portion of the central Appalachian Basin. Int. J. Coal Geol. 1998, 38, 115-136. [CrossRef]

2. Kelafant, J.R.; Boyer, C.M.; Zuber, M.D. Production Potential and Strategies for Coalbed Methane in the Central Appalachian Basin. In Proceedings of the SPE Eastern Regional Meeting; Society of Petroleum Engineers: Charleston, West Virginia, USA, 1988.

3. Zuber, M.D. Production characteristics and reservoir analysis of coalbed methane reservoirs. Int. J. Coal Geol. 1998, 38, 27-45. [CrossRef]

4. Rodvelt, G.D.; Moyers, W.L.; Malamisura, R.; Hagy, C.; Greer, S. Case History: Recompletions in a Virginia Coalbed Methane Field Yields Additional Gas. In Proceedings of the SPE Eastern Regional Meeting; Society of Petroleum Engineers: Charleston, West Virginia, USA, 2009.

5. Holditch, S.A.; Ely, J.W.; Semmelbeck, M.E.; Carter, R.H.; Hinkel, J.; Jeffrey, R.G., Jr. Enhanced recovery of coalbed methane through hydraulic fracturing. In Proceedings of the SPE Annual Technical Conference and Exhibition; Society of Petroleum Engineers: Charleston, West Virginia, USA, 1988.

6. Rogers, R.E.; Ramurthy, K.; Rodvelt, G.; Mullen, M. Coalbed Methane: Principles and Practice (3rd Edition); Oktibbeha Publishing, LLC: Starkville, MS, USA, 2011.

7. Seidle, J. Fundamentals of Coalbed Methane Reservoir Engineering; PennWell Books: Tulsa, OK, USA, 2011.

8. Palmer, I.; Mansoori, J. How permeability depends on stress and pore pressure in coalbeds: A new model. In Proceedings of the SPE Annual Technical Conference and Exhibition; Society of Petroleum Engineers: Colorado Denver, CO, USA, 1996.

9. Pashin, J.C. Variable gas saturation in coalbed methane reservoirs of the Black Warrior Basin: Implications for exploration and production. Int. J. Coal Geol. 2010, 82, 135-146. [CrossRef]

10. Arri, L.E.; Yee, D.; Morgan, W.D.; Jeansonne, M.W. Modeling coalbed methane production with binary gas sorption. In Proceedings of the SPE Rocky Mountain Regional Meeting; Society of Petroleum Engineers: Casper, WY, USA, 1992.

11. Clarkson, C.R.; Bustin, R.M.; Seidle, J.P. Production-data analysis of single-phase (gas) coalbed-methane wells. SPE Res. Eval. Eng. 2007, 10, 312-331. [CrossRef] 
12. Ripepi, N.S. Carbon Dioxide Storage in Coal Seams with Enhanced Coalbed Methane Recovery: Geologic Evaluation, Capacity Assessment and Field Validation of the Central Appalachian Basin. Ph.D. Thesis, Virginia Tech, Blacksburg, VA, USA, 2009.

13. White, C.M.; Smith, D.H.; Jones, K.L.; Goodman, A.L.; Jikich, S.A.; LaCount, R.B.; Schroeder, K.T. Sequestration of carbon dioxide in coal with enhanced coalbed methane recovery a review. Energy Fuels 2005, 19, 659-724. [CrossRef]

14. Gilliland, E.S.; Ripepi, N.; Conrad, M.; Miller, M.J.; Karmis, M. Selection of monitoring techniques for a carbon storage and enhanced coalbed methane recovery pilot test in the Central Appalachian Basin. Int. J. Coal Geol. 2013, 118, 105-112. [CrossRef]

15. Grimm, R.P.; Eriksson, K.A.; Ripepi, N.; Eble, C.; Greb, S.F. Seal evaluation and confinement screening criteria for beneficial carbon dioxide storage with enhanced coal bed methane recovery in the Pocahontas Basin, Virginia. Int. J. Coal Geol. 2012, 90, 110-125. [CrossRef]

16. Louk, K.; Ripepi, N.; Luxbacher, K.; Gilliland, E.; Tang, X.; Keles, C.; Michael, K. Monitoring CO 2 storage and enhanced gas recovery in unconventional shale reservoirs: Results from the Morgan County, Tennessee injection test. J. Nat. Gas Sci. Eng. 2017, 45, 11-25. [CrossRef]

17. Ripepi, N.; Gilliland, E.; Michael, K. Central Appalachian Basin Unconventional (Coal/Organic Shale) Reservoir Small Scale CO2 Injection Test, Presentation. Available online: https:/ / netl.doe.gov / research/ proj?k=FE0006827\&show=ppp (accessed on 28 September 2017).

18. Gardes, R. Multi Seam Coal Bed/Methane Dewatering and Depressurizing Production System. U.S. Patent No. 6,923,275, 2 August 2005.

19. McKee, C.R.; Bumb, A.C. Flow-testing coalbed methane production wells in the presence of water and gas. SPE Form. Eval. 1987, 2, 599-608. [CrossRef]

20. Bang, J.; Mjaaland, S.; Solstad, A.; Hendriks, P.; Jensen, L.K. Acoustic gas kick detection with wellhead sonar. In Proceedings of the SPE Annual Technical Conference and Exhibition; Society of Petroleum Engineers: New Orleans, LA, USA, 1994.

21. Schubert, J.J.; Wright, J.C. Early kick detection through liquid level monitoring in the wellbore. In Proceedings of the IADC/SPE Drilling Conference; Society of Petroleum Engineers: Dallas, TX, USA, 1998.

22. Sarhosis, V.; Jaya, A.A.; Thomas, H.R. Economic modelling for coal bed methane production and electricity generation from deep virgin coal seams. Energy 2016, 107, 580-594. [CrossRef] 